\begin{tabular}{|c|c|}
\hline 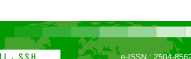 & Malaysian Journal of Social Sciences and Humanities (MJSSH) \\
\hline Malaysian Journal of & Volume 4, Issue 7, November 2019 \\
\hline $\begin{array}{l}\text { Humanities } \\
\text { (MJ - SSH) }\end{array}$ & e-ISSN : 2504-8562 \\
\hline & $\begin{array}{l}\text { Journal home page: } \\
\text { www.msocialsciences.com }\end{array}$ \\
\hline
\end{tabular}

\title{
Effectiveness of Free Maternal Healthcare Programme Under the Successful Delivery Programme in Jigawa State, Nigeria
}

\author{
Muhammad Abdulkadir'1, Ruslan Rainis', Alshammari Eissa Zaidan², Murtala Uba Muhammad³, \\ Yamuna A Kani ${ }^{4}$ \\ ${ }^{1}$ Geography Section, School of Humanities, Universiti Sains Malaysia (USM) \\ 2Geography Department, University of Ha'il Saudi Arabia \\ ${ }^{3}$ Geography Department, Bayero University, Kano, Nigeria \\ ${ }^{4}$ Federal University Dutse, Jigawa State, School of Medicine
}

Correspondence: Muhammad Abdulkhadir (muhammad.abdulkadir@student.usm.my)

\begin{abstract}
In the state effort reduce the number of maternal death, a free child and maternal healthcare programme were introduced called Successful delivery. This main aim of this research is to evaluate if women registered with the programme had a better chance of accessing the services in the state. A crosssectional quantitative study involving household interviews of all women of the reproductive age group (15-49 years) residing in Jigawa state from February to April 2019. Logistic regression analysis at $95 \%$ confidence interval was used to determine the independent associations between the scheme and use of antenatal care, hospital delivery and postnatal care services. Successful delivery program influenced the antenatal care visit as women registered with the schemes are more likely to have maximum of six visit 39.5 times than those who did not and also more likely to have four visit 2.6 times than those without scheme. Hospital delivery is also attached to the scheme as women registered with the scheme is 5.3 times likely to deliver at hospital when compared to those with not. Successful delivery program influence antenatal care visit and hospital base delivery. Nevertheless many of the pregnant women after delivery did not attend postnatal care.
\end{abstract}

Keywords: successful delivery, antenatal care visit, hospital base delivery, postnatal care

\section{Introduction}

The Millennium Development Goals (MDGs) advocate for the reduction of world ratio of the maternal mortality by $75 \%$ from 1990 to the year 2015(Dieleman et al., 2015; Hogan et al., 2010; Organization, 2010) The ratio of the maternal mortality almost reduced by $44 \%$ with an estimated figure of 216 in 2015 and uncertainty interval of $80 \%$ maternal mortality. The lifetime risk of global maternal mortality is significantly reduced from 1 out of 73 to 1 out of 180 (Dieleman et al., 2015) The target of Millennium Development Goals was not achieved by any country in the world but however the ratio of the maternal death was reduced to 3\% after the MDGs declarations.

The Sustainable Development Goals (SDGs) build on the effort of the Millennium Development Gaols therefore it calls for the speeding up of the situation in order to achieved a global ratio of the maternal mortality of 70 per live births by the year 2030 by ending mortalities that are preventable (Asafo \& Adoma, 2019; Assembly, 2015; Organization, 2004). The ratio of the maternal mortality need to be 
reduces by the countries yearly by $7.5 \%$ from 2016 to the year 2030. Appropriate programme and interventions must be put in place in order to achieve this ambitious target which includes financing the interventions, access to the health care and provision of skilled care (Chou et al., 2016; Organization, 2015) The major obstacles to healthcare in many countries especially low and middle income nations is financial constrains. Many countries in Africa have introduced policies of free child and maternal and health in their effort to reduce the mortality (infant and maternal) (Witter, Adjei, Armar-Klemesu, \& Graham, 2009).

In many developing countries the main source of financing health care are user fees(Acharya et al., 2017; Basu, Andrews, Kishore, Panjabi, \& Stuckler, 2012) In the late 1980 and early 1990 the user fees was introduced as a policy for structural adjustment by the World Bank(Dzakpasu, Powell-Jackson, \& Campbell, 2013; Lozano et al., 2012).The user fees in Africa was introduced in 1987 during the Initiative programme of Bamako, jointly financed by United Nations Children Fund and World Health Organisation and this was unanimously adopted by Health Ministers of African Forum(Benjamin, Chineny, Ogochukwu, \& Obinna, 2015; Silva et al., 2011) The policy become accepted and popular in many low income countries because is one of the loan condition set by International Monetary Fund and World Bank for any nations looking for the support of funding. The rationalization for the introduction of user fees in many African Countries was to reduce funding problems and health policy shift ideology which emphasize efficiency (Hardon, 1990).Government budget for the Ministry of Health in many African Countries and Nigeria in particular is not meet up with peoples and population health care needs which led to the introduction and implementation of patient user fee.

Financing of health care in many countries in Africa is reasonably low especially in allocating of $15 \%$ of total expenditure of the government to the sector of health as agreed in Abuja by the African Heads of state in the year 2001(Govender, McIntyre, \& Loewenson, 2008; Odeyemi \& Nixon, 2013; Uzochukwu et al., 2015) .Evidently, user fees generate huge revenue to the government and health institutions and this affected the people disproportionally(Uzochukwu et al., 2015). The fees also reduces accessibility to the health care services and hence the utilization of health service is grossly reduced (Mæstad \& Mwisongo, 2011; Ridde \& Morestin, 2010).

The abolition of the user fees in Africa and reasons for that (abolition) varies from one country to another, in some countries is motivated politically while in some other countries is donor influenced (Hercot, Meessen, Ridde, \& Gilson, 2011; Meessen et al., 2011; Ridde \& Diarra, 2009).Many countries scrap the user fees just to bring essential services closer to the poor population. In 1994 South Africa abolish all user fees for under- 5 children, nursing and pregnant women. Uganda in 2001 suddenly scrapped user fees in all government health institutions. Zambian government abolished fees in facilities in rural areas while government of Burundi scrapped the user fees for child and maternal health (Benjamin et al., 2015; Hutton, 2004; Sharma, 2012). When these fees were abolished there were increased in the utilisation and patronage of the health institution by the patient (Chuma, Musimbi, Okungu, Goodman, \& Molyneux, 2009; Gobah \& Liang, 2011; Riman \& Akpan, 2012).

Jigawa State government of Nigeria make a policy that local government council has to contribute to the state to make fund available for the improvement of health facilities, free ambulance services provision, recruitment of qualified and specialised medical doctors in the field of obstetrics and gynaecology, all this is an effort and attempt to minimise the level of maternal mortality in the state, and the programme is tagged HAIHUWA LAFIYA (successful delivery).

\section{The Free Maternal and Child Health (Successful delivery) Programme in Jigawa State}

Jigawa state government in 2007 launched a programme which tagged as HAIHUWA LAFIYA (successful delivery) the scheme is aiming at providing services for free to all pregnant women and child in the state provided they registered with the programme. This was as a result of high maternal and burden of disease profile in the state. The scheme is to cover all the services ranging from antenatal 
visit to laboratory test during the pregnancy period to 42 days after the termination of the pregnancy. The main aim of the scheme is as follows:

i. To achieve child and maternal mortality in the state by increasing the accessibility to health institutions and scarping the service fees.

ii. Provision of skilled and qualified health attendant during pregnancy and after the delivery

iii. To provide free ambulances services which will convey the patient from the home to the health institution

iv. To help in achieving the goals of Millennium Development Goals.

The pregnant women were exempted from paying all user fees provided have registered with the programme(Okereke, Tukur, Aminu, et al., 2015). The rationale of this research therefore is to determine the effectiveness of registration with the programme on access to maternal healthcare services. The study hypothesise that pregnant women who are registered with the Successful delivery program have more access to antenatal care facility-based delivery and postnatal care.

\section{Materials and methods}

\section{Study area}

The state of Jigawa was removed from the State of Kano on 27 August, 1991 as one of the additional nine states by the then military government. The state is situated in the north-western region of the country, it has share boarders with Katsina and Kano from the west, from the north east it share boarder with Yobe state and from the east is Bauchi state, the state share international border with Niger republic from the north (Figure 1). The state has two seasons, October - May is dry seasons while JuneSeptember is a rainy seasons with high temperature of about $42^{\circ} \mathrm{c}$ while the state experienced lower temperature during the rainy season with $10^{\circ} \mathrm{c}$ (Okereke, Tukur, Oginni, \& Obonyo, 2015). According to the population census of 2006 the state is $8^{\text {th }}$ in terms of population with the $2,215,897(51 \%)$ as males and 2,132,752 (49\%) as female (Commission, 2006) Jigawa State is a rural state with about $85 \%$ of its population live in rural environment.

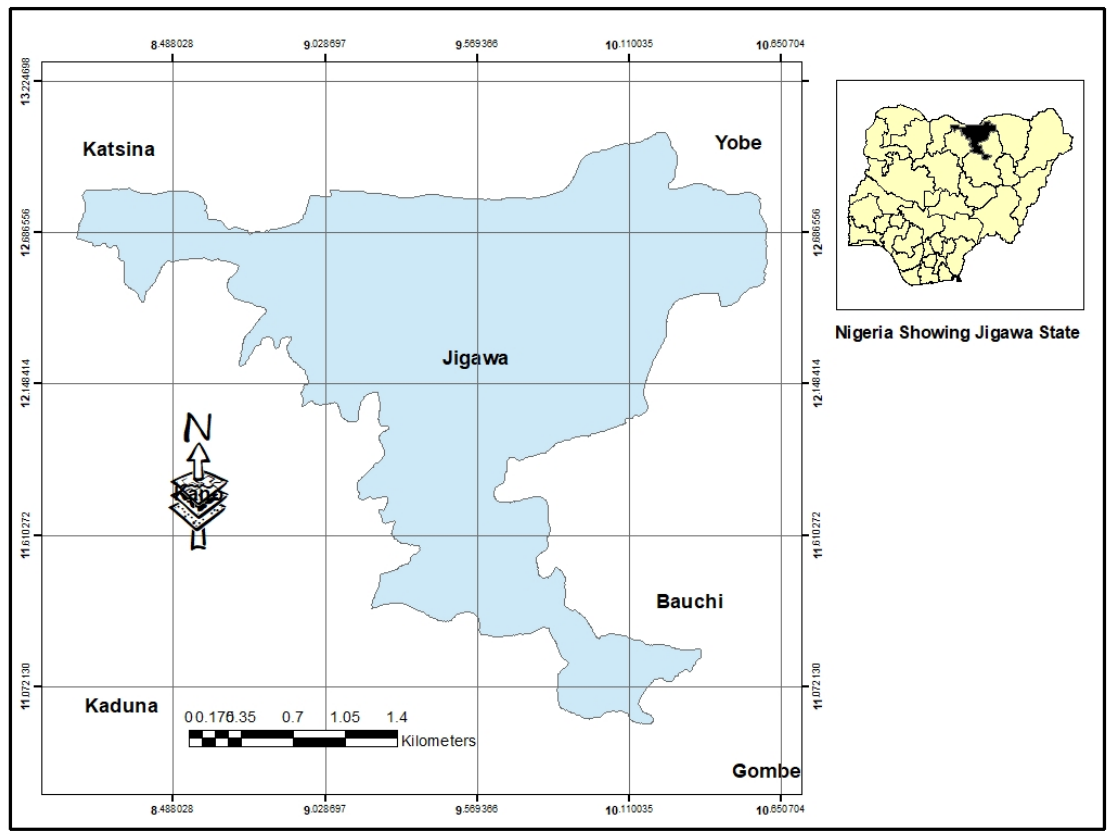

Figure 1: Jigawa State Nigeria 
In terms of health care services, the state has three ties of health facilities, the tertiary health facilities which is under the jurisdiction of the federal government (With only one federal Medical Centre) and secondary health facilities which under the supervision of the state government (The state has 16 general hospital and one specialist hospital) while the primary health care is under the jurisdiction of the local government (Dogara \& Ocheje, 2016; Makinde, Sule, Ayankogbe, \& Boone, 2018).Due to the poverty nature of the state, there were less private health facilities in Jigawa state. The ministry of health and agency for Primary Health care are responsible for executing and formulating policies related to health in the state and also translating federal government health policies for implementation. It worth noting that the state now operate under one roof system which a primary health (centre) is expected to be provided in each ward of the state (Makinde et al., 2018).

\section{Study design and Sampling Procedure}

The study was conducted using a cross sectional study which is quantitative in nature from the month of February to April 2019. The study make used of women of reproductive age of 15 to 49 years and have children of 12 months to 3 years of age. 343 women were administered with house hold questionnaires.

The multistage sampling was adopted as a method by the study. The towns headquarter of Hadejia of North east district and Dutse of Central district were selected purposely. A four sub district was selected using a stratified method of sampling base on their categorisation. Simple random method of sampling was used to select one each from the compiled name of communities. In order to select the houses, the systematic method of sampling was used. The research selected nursing mothers within every third house fell within the target group and thereby interviewed. If there is above one entitled respondent the research randomly selected one of them by balloting. In the absence of the suitable (eligible) respondent the researcher moves to the next house. Hausa local language was used for the interview.

\section{Sample size determination}

In order to determine the size of sampling hospital base deliveries (66.3\%) was used where:

$\mathrm{t}=$ confidence interval $(95 \%)$

$\mathrm{n}=$ sample size

$\mathrm{p}=$ estimated of $66.3 \%$ hospital deliveries

The sample size of nursing mothers (343) is estimated below

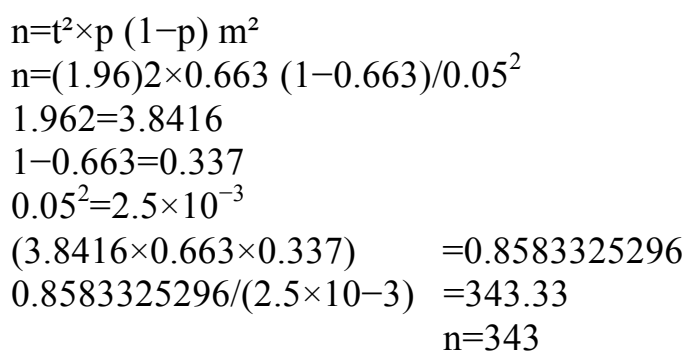

\section{Instruments for Data collection}

The research designed questionnaire and pretested in Gumel, headquarter of North-west district. The pretesting is to ensure reliability and validity and ambiguities checking. The choice of Gumel district was because it has similarity in terms of characteristics with the area of the study. Before the application of the questionnaire on the field, the researcher addressed all the weaknesses revealed as a result of pretesting. Two research assistant were recruited and trained in local language of Hausa. An interview on average took approximately 25 minutes per respondent. The questionnaire consist of 3 
sections: section of socio-demographic variables, section was on registration with the programme and the last section was question on the antenatal visit accessibility and delivery place and postnatal service. The researcher informed and sought consent from the respondent before the commencement of the interview.

\section{Outcome variables}

In order to assess the effectiveness of successful delivery programme on the maternal health care usage three variables out comes were used: Hospital base delivery, Antenatal care and postnatal care. Hospital base delivery is the delivery supervised and attended by skilled and professionals in the hospital. Antenatal care is the routine medical attention receiving by pregnant women, antenatal care include receiving folic and tetanus injection while postnatal care is the medical care which women received after the termination of the pregnancy. Hospital base delivery coded as delivery place and home or hospital and antenatal was coded yes/no (means that women received the care or not). Questions was ask in order to know and measure if pregnant women satisfy with the services provided in the hospital, a three level question was asked with high satisfaction, average satisfaction and dissatisfaction.

\section{Data entry and statistical analysis}

The result of the interview were later coded and in put in to excel (Microsoft 2016) and exported into Statistical software (SPSS), out of 343 questionnaires only one is rejected because it is uncompleted. The result was later subjected into statistical analysis which consists of descriptive and inferential statistics. The research used Binominal and multinomial logistic regression in order to correlate the scheme (Successful delivery) and antenatal visit, postnatal care and hospital base delivery. The confidence interval of $95 \%$ was used by the research and 0.05 significant values as $\mathrm{P}$.

\section{Ethics and consent to participate}

The ethical procedure was fully observed by the research as the study has undergo through the ethical committee of state ministry of Jigawa state, and the ministry were satisfied and approval were granted. The confidentiality of the respondents was guarantee. In addition, participants were also assured that, this will not affect their relationship with institutions or the Successful delivery programme. The respondents were participated voluntarily.

\section{Results}

The result of the study indicates that $83 \%$ of the pregnant women are married and $50 \%$ are living in urban areas. The study also shows that (Table. 1) $40 \%$ of the pregnant women are workers and about $37 \%$ never gone to school. Education, marital status, residence and employment influence also access to the scheme (Successful delivery) $\mathrm{P}=0.000$ as shown in Table. 1

Pregnant women engaged in labour intensive are more likely 2.149 times to registered and participated from the scheme than the unemployed women while those with professional job registered and benefited with the scheme 3.039 times. Additionally Table 2 shows that non married pregnant women do not have access and registered with the scheme than the married pregnant women (12.288 times). 
Table 1: Association between socio-demographic variables of respondent and Access to free maternal Service

\begin{tabular}{lccc}
\hline Variables & Freauencv & Registered with & Not Registered \\
\hline Age & & & $\mathrm{P}=0.058$ \\
$15-24$ & $104(30)$ & $30(23)$ & $74(35)$ \\
$25-34$ & $166(49)$ & $71(54)$ & $95(45)$ \\
$35-49$ & $72(21)$ & $30(23)$ & $42(20)$ \\
Residence & & & $\mathrm{P}=0.000$ \\
Urban & $195(57)$ & $97(74)$ & $100(47)$ \\
Rural & $145(43)$ & $34(26)$ & $111(53)$ \\
Status & & & $\mathrm{P}=0.000$ \\
Married & $283(83)$ & $125(95)$ & $158(75)$ \\
Single & $59(17)$ & $6(5)$ & $53(25)$ \\
Employment & & & $\mathrm{P}=0.000$ \\
Unemployed & $112(32)$ & $27(21)$ & $85(40)$ \\
Labour intensive & $95(28)$ & $28(21)$ & $67(32)$ \\
Skilled job & $135(40)$ & $76(58)$ & $59(28)$ \\
Education & & & $\mathrm{P}=0.000$ \\
Never & $126(37)$ & $23(18)$ & $103(49)$ \\
Primary & $106(31)$ & $36(27)$ & $70(33)$ \\
Secondary & $92(27)$ & $55(42)$ & $37(17)$ \\
Tertiary & $18(5)$ & $17(13)$ & $1(1)$ \\
Religion & & & $\mathrm{P}=0.348$ \\
Christian & $241(71)$ & $98(75)$ & $143(68)$ \\
Muslim & $80(23)$ & $27(20)$ & $53(25)$ \\
Traditionalist & $21(6)$ & $6(5)$ & $15(7)$ \\
Programme status & & & \\
Yes & $131(38)$ & & \\
No & $211(62)$ & & \\
\hline
\end{tabular}

Table 2 : Binary Logistic regression of marital and Educational status, Women's resident and Employment with Successful delivery Programme

\begin{tabular}{lllllllll}
\hline Variable & $\begin{array}{l}\text { Binary } \\
\text { Logistic }\end{array}$ & SD & NE & d/f & Significance & $\begin{array}{l}\text { EXP } \\
\text { (B) }\end{array}$ & Lower & Upper \\
\hline Education & & & 46.542 & 3 & 0 & & & \\
Primary* & -4.388 & 1.141 & 14.784 & 1 & 0 & 0.012 & 0.001 & 0.116 \\
Secondary & -3.362 & 1.132 & 8.821 & 1 & 0.003 & 0.035 & 0.004 & 0.319 \\
Tertiary & -1.999 & 1.13 & 3.13 & 1 & 0.077 & 0.136 & 0.015 & 1.24 \\
Marital status (Married/not) & 2.509 & 0.532 & 22.251 & 1 & 0 & 12.228 & 4.333 & 34.845 \\
Employment (Unemployed) & & & 10.463 & 2 & 0.005 & & & \\
Un skilled job & 0.765 & 0.38 & 4.063 & 1 & 0.044 & 2.149 & 1.021 & 4.522 \\
Skilled job & 1.112 & 0.347 & 10.273 & 1 & 0.001 & 3.039 & 1.54 & 5.997 \\
Residence (Rural/urban & 1.112 & 0.307 & 1.711 & 1 & 0.191 & 0.67 & 0.367 & 1.221 \\
\hline
\end{tabular}

Table 3 shows that pregnant women registered with the successful delivery programme 39.5 times are more likely to have access and received at least four antenatal care or more than four than those pregnant women not registered with scheme. The antenatal care includes tetanus injection and receipt of folic acid during pregnancy. Pregnant women registered with the scheme are 62-71 times likely to receipt folic acid and get tetanus injection than those pregnant women not registered with the scheme. 
In terms of hospital delivery, pregnant women who registered with the scheme are more likely to deliver at hospital 5.281 times than those pregnant women not registered with successful delivery programme ad depicted in Table 4. The percentages of pregnant women registered with the scheme for postnatal care as indicated in Table 5 was very low at $8.5 \%$. The negative association was shown in Table 6 between the scheme and postnatal care as pregnant women not registered with the Successful delivery programme are $1 / 0.83$ (12.04) times to attend postnatal care compared to those pregnant women registered with the scheme.

Table 3 : Binary logistic regression of antenatal and Successful delivery Programme

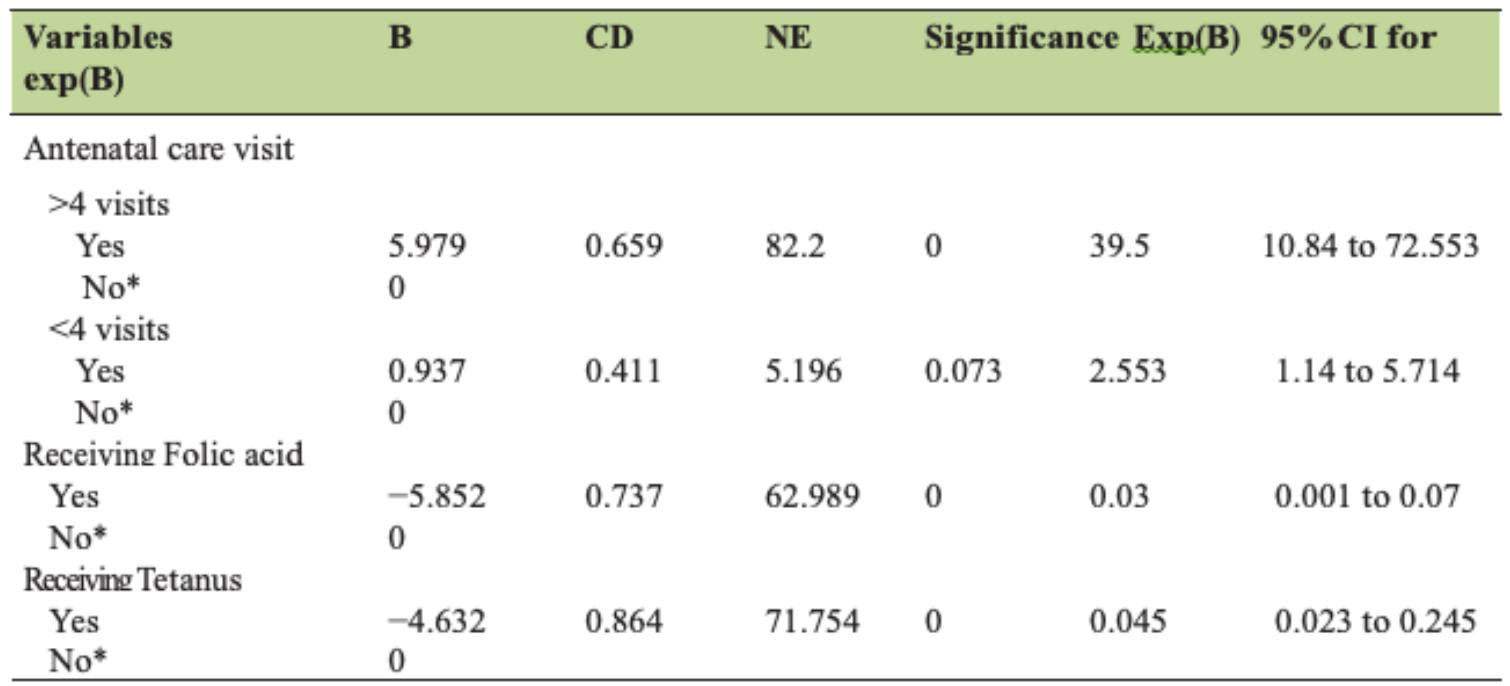

Table 4 : Multivariate Logistic Regression between Successful Delivery and Hospital based delivery

\begin{tabular}{lllllll}
\hline Variable & B & CD & NE & Significance & $\operatorname{Exp(B)}$ & $\begin{array}{l}\mathbf{9 5 \%} \text { CI for } \\
\exp (\mathbf{B})\end{array}$ \\
\hline $\begin{array}{l}\text { Place of } \\
\text { delivery }\end{array}$ & & & & & & \\
$\begin{array}{l}\text { Hospital } \\
\text { Home* }\end{array}$ & $\begin{array}{l}3.967 \\
0\end{array}$ & 0.42 & 89.34 & 0 & 5.281 & \\
\hline
\end{tabular}

Table 5 : Association between Successful delivery programme and postnatal care

\begin{tabular}{lllll}
\hline Variables & Insured & Not insured & Total & P values \\
\hline $\begin{array}{l}\text { Postnatal } \\
\text { Yes }\end{array}$ & $29(8 \%)$ & $63(18.5 \%)$ & 92 & 0.007 \\
$(26.5 \%)$ & $102(30 \%)$ & $148(43.5 \%)$ & 250 & \\
$\begin{array}{l}\text { No } \\
(73.5 \%)\end{array}$ & $131(38 \%)$ & $211(62 \%)$ & $342(100 \%)$ & \\
\hline Total & & & & \\
\hline
\end{tabular}


Table 6 : Binary Logistic Regression between Successful Delivery programme and postnatal care

\begin{tabular}{lllllll}
\hline Variable & B & CD & NE & Significance & $\operatorname{Exp}(\mathbf{B})$ & $\begin{array}{l}\mathbf{9 5 \%} \text { CI for } \\
\exp (\mathbf{B})\end{array}$ \\
\hline $\begin{array}{l}\text { Postnatal } \\
\text { care use }\end{array}$ & & & & & & \\
$\begin{array}{l}\text { Yes } \\
\text { No* }\end{array}$ & -2.492 & 0.266 & 88.023 & 0.014 & 0.083 & 0.049 to 0.139 \\
\hline
\end{tabular}

Table 7 : Logistic Regression (multivariate)

\begin{tabular}{lllllllll}
\hline Variable & B & CD & NE & d/f & Significance & Exp(B) & Lower & Upper \\
\hline Education & & & 14.171 & 3 & 0.003 & & & \\
Primary(1) & -4.535 & 2.116 & 7.592 & 1 & 0.032 & 0.011 & 0 & 0.679 \\
Secondary(2) & -3.649 & 2.081 & 3.075 & 1 & 0.08 & 0.026 & 0 & 1.536 \\
$\begin{array}{l}\text { Tertiary(3) } \\
\text { Employment }\end{array}$ & -2.094 & 2.091 & 1.003 & 1 & 0.317 & 0.123 & 0.002 & 7.427 \\
$\begin{array}{l}\text { Professional(1) } \\
\text { Unskilled(2) }\end{array}$ & 1.693 & 0.692 & 5.979 & 1 & 0.014 & 5.435 & 1.399 & 21.109 \\
$\begin{array}{l}\text { Marital status } \\
\text { (married) }\end{array}$ & 1.226 & 0.565 & 4.72 & 1 & 0.03 & 3.409 & 1.128 & 10.307 \\
$\begin{array}{l}\text { Residence (Urban) } \\
\text { Antenatal Care(Yes) }\end{array}$ & 0.931 & 0.831 & 12.957 & 1 & 0 & 19.902 & 3.905 & 101.419 \\
$\begin{array}{l}\text { Place of Delivery } \\
\text { (Hospital) }\end{array}$ & 0.526 & 0.856 & 2.276 & 1 & 0.131 & 2.313 & 0.778 & 6.875 \\
Postnatal (Yes) & 0.141 & 0.789 & 7.362 & 1 & 0.007 & 1.117 & 0.725 & 2.552 \\
\hline
\end{tabular}

\section{Interpretations}

Table 6 also takes confounding factors (Variables) into consideration and interpreted as, pregnant women with professional jobs have access and registered with the successful delivery programme than those pregnant women who are unemployed 5.435 times, labour intensive pregnant women have registered with the scheme compared to women who are unemployed 3.409 times, pregnant women registered with the successful delivery programme compared to those who did not are 2.004 times access and attend antenatal care, where as pregnant women registered with the programme compared with those not registered with the programme are 1.117 times to deliver at hospital. Table 7 confounding factors are socio-demographic variables (Residence, employment and marital status and women's education).

\section{Discussion}

The research aimed at finding if pregnant women who have registered with Successful delivery (Haihuwa Lafiya) programme of Jigawa state, Nigeria have access to the services of the health care at the health institutions. Health seeking behaviours is largely influence by socio-demographic variables of the pregnant women, variables like employment and marital status, women's level of education, women's age, residence and religion are greatly affect the pregnant women decision. This study found that successful delivery programme is directly associated with the married women, women with professional job, and who are employed. This is because most of the pregnant women involved in this study are live in the city and are educated and therefore they the existence and benefit of the scheme (Dixon, Tenkorang, \& Luginaah, 2013). 
The research evaluated on how the free maternal and child health programme of Jigawa state, Nigeria under the Successful delivery programme (Haihuwa lafiya) can be use to improve the participation and accessibility of women to the use of health institution during pregnancy for maternal services. Free maternal health services play an important role in the woman's health seeking behaviour. Pregnant women who registered with scheme have access to routine medical attention (Antenatal), delivery at hospital and care after delivery (Postnatal) while women who did not registered with the scheme are not. This is because of the scrapping of the service fees which normally denied women's accessibility to the maternal services.

This study corroborated with the previous studies which reported that pregnant women who have access to free maternal health have higher chance of attending and receiving antenatal care, deliver at hospital and service after delivery. A study by (Comfort, Peterson, \& Hatt, 2013) which support this research finding indicated that pregnant women who have access to free maternal services compared to those who have not are $47 \%$ to have access with routine medical attention, deliver at hospital and service after delivery.

For the health of the child and mother the routine medical care (Antenatal) is very important. The complication signs are normally detected during the visit and to know right action to take, it is at the routine medical check up by the pregnant women that any diseases which are danger to the health of mother and the child are treated. Even the food types which pregnant women need to takes in addition to the numerous precautionary measures which will help in successful delivery. Therefore, safe delivery is directly related with the receiving antenatal care (Twum, Qi, Aurelie, \& Xu, 2018).Many studies have examined the relationship between free maternal health services and antenatal visit accessibility, hospital delivery but were unable to study the four antenatal care visits. Therefore this study is contribution to the branch of knowledge by finding that pregnant women who registered with the successful delivery program have higher chance of receiving maternal services.

The finding of this study is not unique to Jigawa state, Nigeria only, the declaration of free maternal services by Kenya, the hospital delivery rose to a significant rate(Lang'at \& Mwanri, 2015) Comport and co conducted a systematic review in Africa ,Asian, Europe and South American regions which they evaluated the effectiveness of free maternal services have found a very good and positive relationship between hospital base delivery, routine medical care (Antenatal) and service after delivery (Postnatal) (Comfort et al., 2013).

The finding of the study indicated that the relationship between free maternal service and postnatal, the possibility of mothers to come for the service (postnatal) was very low when compared with the hospital delivery and antenatal visit. This is because mothers registered with free maternal service encounter not complications during childbirth; therefore they assumed no need to attend postnatal care. Note that for the good health of the child and that of mother the postnatal care service is very important. Unfortunately many mothers in Sub Saharan African did not bother to attend medical service after delivery but they prefer to attend antenatal and deliver at hospital. A study in Congo found that pregnant women as high as $93 \%$ do received and attend antenatal and deliver at hospital, surprisingly only $35 \%$ attend medical service after delivery(Bayu, Adefris, Amano, \& Abuhay, 2015; Mannava, Durrant, Fisher, Chersich, \& Luchters, 2015) Studies in Kenya also reported that only 20\% of mothers do attend postnatal service(Finlayson \& Downe, 2013; UNESCO, 2012).

This research strength is therefore, it gives highlight of the effectiveness of the successful delivery programme on maternal services (which cover all aspect). Multistage sampling was used by the research which enables the researcher select participant among the communities who participated in the study. The limitation of the study is that the research did not consider the quality of the services provided. 


\section{Conclusions}

The result of this study shows that women who have registered with Successful delivery programme (Haihuwa lafiya) in Jigawa state at least had four routine medical attentions (Antenatal), and most of the registered women deliver at hospital by the skill personnel. Sadly, many of the women did not go service after delivery (Postnatal). The study recommended that there need to enlighten the women on the benefit of the programme and also educate them about the importance of receiving postnatal care.

\section{References}

Acharya, B., Maru, D., Schwarz, R., Citrin, D., Tenpa, J., Hirachan, S., . . . Halliday, S. (2017). Partnerships in mental healthcare service delivery in low-resource settings: developing an innovative network in rural Nepal. Globalization and health, 13(1), 2.

Asafo, A. J., \& Adoma, D. B. (2019). Determinants of women's perceived satisfaction on Antenatal care in urban Ghana: A cross-sectional study.

Assembly, G. (2015). sustainable Development goals. SDGs), Transforming our world: the, 2030.

Basu, S., Andrews, J., Kishore, S., Panjabi, R., \& Stuckler, D. (2012). Comparative performance of private and public healthcare systems in low-and middle-income countries: a systematic review. PLoS medicine, 9(6), e1001244.

Bayu, H., Adefris, M., Amano, A., \& Abuhay, M. (2015). Pregnant women's preference and factors associated with institutional delivery service utilization in Debra Markos Town, North West Ethiopia: a community based follow up study. BMC pregnancy and childbirth, 15(1), 15.

Benjamin, U., Chineny, O., Ogochukwu, E., \& Obinna, O. (2015). Free maternal and child health services in Enugu state, south East Nigeria: experiences of the community and health care providers. Int J Med Health Sci Res, 2(9), 158-170.

Chou, D., Tunçalp, Ö., Firoz, T., Barreix, M., Filippi, V., von Dadelszen, P., . . . Say, L. (2016). Constructing maternal morbidity-towards a standard tool to measure and monitor maternal health beyond mortality. BMC pregnancy and childbirth, 16(1), 45.

Chuma, J., Musimbi, J., Okungu, V., Goodman, C., \& Molyneux, C. (2009). Reducing user fees for primary health care in Kenya: Policy on paper or policy in practice? International journal for equity in health, 8(1), 15.

Comfort, A. B., Peterson, L. A., \& Hatt, L. E. (2013). Effect of health insurance on the use and provision of maternal health services and maternal and neonatal health outcomes: a systematic review. Journal of health, population, and nutrition, 31(4 Suppl 2), S81.

Commission, N. P. (2006). Population census report. Abuja, Nigeria.

Dieleman, J., Murray, C., Haakenstad, A., Graves, C., Johnson, E., \& Templin, T. (2015). Financing global health 2014: shifts in funding as the MDG era closes. Seattle, WA: Institute for Health Metrics and Evaluation.

Dixon, J., Tenkorang, E. Y., \& Luginaah, I. (2013). Ghana's National Health Insurance Scheme: a national level investigation of members' perceptions of service provision. BMC International Health and Human Rights, 13(1), 35.

Dogara, M. M., \& Ocheje, A. (2016). Prevalence of malaria and risk factors among patients attending Dutse General Hospital, Jigawa State, Nigeria. Int J Pub Environ Health, 11, 270-277.

Dzakpasu, S., Powell-Jackson, T., \& Campbell, O. M. (2013). Impact of user fees on maternal health service utilization and related health outcomes: a systematic review. Health policy and planning, 29(2), 137-150.

Finlayson, K., \& Downe, S. (2013). Why do women not use antenatal services in low-and middleincome countries? A meta-synthesis of qualitative studies. PLoS medicine, 10(1), e1001373.

Gobah, F. F., \& Liang, Z. (2011). The National Health Insurance Scheme in Ghana: prospects and challenges: a cross-sectional evidence. Global Journal of Health Science, 3(2), 90.

Govender, V., McIntyre, D., \& Loewenson, R. (2008). Progress towards the Abuja target for government spending on health care in East and Southern Africa. Cape Town, SA: EQUINET.

Hardon, A. (1990). Ten best readings in... the Bamako initiative. Health policy and planning, 5(2), 186-189. 
Hercot, D., Meessen, B., Ridde, V., \& Gilson, L. (2011). Removing user fees for health services in low-income countries: a multi-country review framework for assessing the process of policy change. Health policy and planning, 26(suppl_2), ii5-ii15.

Hogan, M. C., Foreman, K. J., Naghavi, M., Ahn, S. Y., Wang, M., Makela, S. M., . . Murray, C. J. (2010). Maternal mortality for 181 countries, 1980-2008: a systematic analysis of progress towards Millennium Development Goal 5. The Lancet, 375(9726), 1609-1623.

Hutton, G. (2004). Charting the path to the World Bank's "No blanket policy on user fees": a look over the past 25 years at the shifting support for user fees in health and education, and reflections on the future. London, DFID Health Systems Resource Centre.

Lang'at, E., \& Mwanri, L. (2015). Healthcare service providers' and facility administrators' perspectives of the free maternal healthcare services policy in Malindi District, Kenya: a qualitative study. Reproductive health, 12(1), 59.

Lozano, R., Naghavi, M., Foreman, K., Lim, S., Shibuya, K., Aboyans, V., . . Ahn, S. Y. (2012). Global and regional mortality from 235 causes of death for 20 age groups in 1990 and 2010: a systematic analysis for the Global Burden of Disease Study 2010. The Lancet, 380(9859), 20952128.

Mæstad, O., \& Mwisongo, A. (2011). Informal payments and the quality of health care: mechanisms revealed by Tanzanian health workers. Health policy, 99(2), 107-115.

Makinde, O. A., Sule, A., Ayankogbe, O., \& Boone, D. (2018). Distribution of health facilities in Nigeria: implications and options for universal health coverage. The International journal of health planning and management, 33(4), e1179-e1192.

Mannava, P., Durrant, K., Fisher, J., Chersich, M., \& Luchters, S. (2015). Attitudes and behaviours of maternal health care providers in interactions with clients: a systematic review. Globalization and health, 11(1), 36.

Meessen, B., Hercot, D., Noirhomme, M., Ridde, V., Tibouti, A., Tashobya, C. K., \& Gilson, L. (2011). Removing user fees in the health sector: a review of policy processes in six sub-Saharan African countries. Health policy and planning, 26(suppl_2), ii16-ii29.

Odeyemi, I., \& Nixon, J. (2013). Assessing equity in health care through the national health insurance schemes of Nigeria and Ghana: a review-based comparative analysis. International journal for equity in health, 12(1), 9.

Okereke, E., Tukur, J., Aminu, A., Butera, J., Mohammed, B., Tanko, M., . . Egboh, M. (2015). An innovation for improving maternal, newborn and child health $(\mathrm{MNCH})$ service delivery in Jigawa State, northern Nigeria: a qualitative study of stakeholders' perceptions about clinical mentoring. BMC health services research, 15(1), 64.

Okereke, E., Tukur, J., Oginni, A. B., \& Obonyo, B. (2015). Evaluating Health Workers' Knowledge Following the Introduction of Clinical Mentoring in Jigawa State, Northern Nigeria. African journal of reproductive health, 19(3), 118-125.

Organization, W. H. (2004). Making pregnancy safer: the critical role of the skilled attendant: a joint statement by WHO, ICM and FIGO: World Health Organization.

Organization, W. H. (2010). PMTCT strategic vision 2010-2015: preventing mother-to-child transmission of HIV to reach the UNGASS and Millennium Development Goals: moving towards the elimination of paediatric HIV, December 2009.

Organization, W. H. (2015). Strategies towards ending preventable maternal mortality (EPMM).

Ridde, V., \& Diarra, A. (2009). A process evaluation of user fees abolition for pregnant women and children under five years in two districts in Niger (West Africa). BMC health services research, $9(1), 89$.

Ridde, V., \& Morestin, F. (2010). A scoping review of the literature on the abolition of user fees in health care services in Africa. Health policy and planning, 26(1), 1-11.

Riman, H. B., \& Akpan, E. S. (2012). Healthcare financing and health outcomes in Nigeria: A state level study using multivariate analysis.

Sharma, A. (2012). User fee impact on equitable access to care: A review. Journal of Health Management, 14(1), 43-49.

Silva, H. T., De Paepe, P., Soors, W., Lanza, O. V., Closon, M.-C., Van Dessel, P., \& Unger, J.-P. (2011). Revisiting health policy and the World Bank in Bolivia. Global Social Policy, 11(1), $22-$ 44. 
Twum, P., Qi, J., Aurelie, K. K., \& Xu, L. (2018). Effectiveness of a free maternal healthcare programme under the National Health Insurance Scheme on skilled care: evidence from a crosssectional study in two districts in Ghana. BMJ open, 8(11), e022614.

UNESCO, H. (2012). Health Education Clearinghouse. Realising Sexual and Reproductive Health Rights in Kenya. Nairobi: Kenya National Commission on Human Rights, 48-49.

Uzochukwu, B., Ughasoro, M., Etiaba, E., Okwuosa, C., Envuladu, E., \& Onwujekwe, O. (2015). Health care financing in Nigeria: Implications for achieving universal health coverage. Nigerian journal of clinical practice, 18(4), 437-444.

Witter, S., Adjei, S., Armar-Klemesu, M., \& Graham, W. (2009). Providing free maternal health care: ten lessons from an evaluation of the national delivery exemption policy in Ghana. Global Health Action, 2(1), 1881. 